\title{
PROFISSIONAL DA INFORMAÇÃO NO LIMIAR DO SÉCULO XXI: enfoque nos periódicos brasileiros em biblioteconomia e ciência da informação (1995/2002)
}

\author{
PROFESSIONAL WORKERS IN THE BEGINING OF THE 21ST CENTURY: \\ an special view of the brazilian librarianship and information science
} periodicals (1995/2002)

\author{
Maria Lourdes Blatt Ohira \\ Bacharel em Biblioteconomia pela UDESC. \\ Mestre em Administração de Sistemas de Informação pela PUCCAMP. \\ Professora do Curso de Biblioteconomia da UDESC. \\ $\underline{\text { f2mlbh@udesc.br }}$ \\ Noêmia Schoffen Prado \\ Bacharel em Biblioteconomia pela UDESC. \\ Mestre em Administração pela UDESC. \\ Professora do Curso de Biblioteconomia da UDESC. \\ r4nsp@,udesc.br \\ Luciana Schmidt \\ Acadêmica do Curso de Biblioteconomia da UDESC. \\ Bolsista do Programa de Iniciação Científica PROBIC/CNPq
}

\begin{abstract}
RESUMO
Apresenta como o tema Profissional da Informação foi abordado nos periódicos brasileiros de Biblioteconomia e Ciência da Informação publicados no período de 1995 a 2002. A avaliação da produção científica envolveu a análise dos seguintes aspectos: produtividade dos autores, tipo de autoria, média de citações por artigo, tipos de documentos citados, núcleo de periódicos mais citados. Os resultados revelaram que a Revista Transinformação publicou maior número de artigos sobre o tema. Os anos de 1996 e 2000 destacaram-se com maior produção no período. A autoria única prevalece com $73 \%$ da produção. Os autores utilizam nas citações os artigos de periódicos com 45\%, seguido dos livros e/ou capítulos de livros, com uma média de 1 a 20 referências por artigo. A influência estrangeira aparece em $48 \%$ dos documentos citados. A Revista Ciência da Informação destaca-se como periódico brasileiro mais citado. Os resultados da pesquisa podem contribuir para a adequação dos currículos dos cursos de graduação em Biblioteconomia.
\end{abstract}

PALAVRAS-CHAVE: Profissional da informação. Competência profissional. Periódicos científicos. Produção científica.

\section{INTRODUÇÃO}

A partir da criação do Special Interest Group of the Modern Information Professional (FID/MIP) pela Federação Internacional de Informação e Documentação - FID (International Federation for Information and Documentation) e da assinatura da Resolução de Tókyo, as 
discussões em torno do perfil do profissional da informação para atuar na Sociedade da Informação e do Conhecimento, passou a ser discutido em nível internacional e nacional (SANTOS, 1996).

No Brasil, a ABECIN - Associação Brasileira de Educação em Ciência da Informação, discutiu o tema em vários encontros regionais e nacionais reunindo representantes dos países do MERCOSUL, no sentido de definir os estudos de harmonização curricular para os Cursos de Biblioteconomia e Ciência da Informação. A partir da aprovação da LDB - Leis de Diretrizes e Bases da Educação Nacional, em 1996, foi designada pelo MEC - Ministério da Educação, uma Comissão de Especialistas para elaboração das diretrizes curriculares nacionais para a área de Ciência de Informação, para os cursos de Biblioteconomia, Arquivologia e Museologia, visando à definição das competências e habilidades gerais e específicas que deve possuir o graduado de cada curso, sendo as mesmas aprovadas em 3 de abril de 2001 (MINISTÉRIO DA EDUCAÇÃO, 2001).

Paralelo aos estudos de harmonização curricular, a ABECIN realizou uma pesquisa com os cursos de Biblioteconomia do Brasil, no sentido de conhecer o perfil do profissional da informação almejado pelos mesmos. Para a realização da pesquisa, os cursos foram reunidos por coordenações regionais da ABECIN, ficando a cargo das mesmas a coleta, o tratamento e a discussão dos dados. Na Região Sul a pesquisa foi realizada por Maia \& Ohira (1998, p. 3), a partir do formulário elaborado pela referida Associação e enviado aos seis cursos de Biblioteconomia: UDESC, UFSC, UEL, UFPR, UFRGS, FURG. Os resultados foram apresentados no V Encontro Nacional do Ensino de Biblioteconomia e Ciência da Informação, realizado em São Carlos - SP, com o tema central a formação do Moderno Profissional da Informação. A pesquisa revelou que o perfil almejado pelos cursos de Biblioteconomia da Região Sul deve possuir as seguintes características: "atualizado; criativo; com atuação interdisciplinar; empreendedor; ético; fluente em sua própria língua; inovador; orientado ao usuário; proativo e preocupado com os fins".

A partir dos eventos acima mencionados, grande quantidade de produção envolvendo o tema "Moderno Profissional da Informação" passou a ser materializado principalmente sob a forma de artigos de periódicos. Para Nassri et al. (2000, p. 51), a produção científica "tem a finalidade de promover a inovação, a mudança, necessitando para isto, da divulgação do conhecimento científico e tecnológico". Os periódicos, publicações que realizam esta tarefa, assumem então uma enorme importância na promoção da rápida expansão do conhecimento produzido. No sentido de conhecer como o tema está sendo abordado pelos periódicos brasileiros da área de Biblioteconomia e Ciência da Informação, foi selecionado um periódico 
da área publicado em cada região geográfica do Brasil, com o objetivo de conhecer a divulgação e abordagem do tema profissional da informação no período de 1995 a 2002, complementado com os seguintes objetivos específicos:

- Levantar a produtividade dos autores e o tipo de autoria;

- Identificar o crescimento da produção no período;

- Conhecer as instituições de origem dos autores;

- Verificar a média de referências utilizadas pelos autores dos artigos;

- Identificar os tipos de documentos utilizados nas citações bibliográficas;

- Detectar a proporção da influência estrangeira nos artigos analisados;

- Levantar o núcleo de periódicos e os autores mais citados no conjunto das referências bibliográficas.

\section{MÉTODO}

Pesquisa de natureza documental, por levantar nos periódicos brasileiros especializados em Biblioteconomia e Ciência da Informação, publicados no período de 1995 a 2002, os artigos que enfocam o tema Profissional da Informação e assim conhecer o comportamento da produção científica nesse período.

Um levantamento preliminar foi realizado com o objetivo de identificar a produção no período de 1990 a 2002, como também, para identificar o título do periódico com maior número de artigos publicados, por região geográfica do Brasil. Foram consultados os seguintes periódicos:

- Região Sul: Encontros Bibli (UFSC); Informação \& Informação (UEL); Revista de Biblioteconomia e Comunicação (UFRGS); Biblos (FURG); Revista ACB: Biblioteconomia em Santa Catarina (ACB);

- Região Sudeste: Transinformação (PUCCAMP); Revista Brasileira de Biblioteconomia e Documentação (FEBAB); DaTaGramaZero (IASI); Perspectiva em Ciência da Informação (UFMG);

- Região Centro Oeste: Revista de Biblioteconomia de Brasília (ABDF/UNB); Ciência da Informação (IBICT);

- Região Nordeste: Informação \& Sociedade: estudos (UFPB);

- Região Norte: Não foi identificado nenhum título de periódico 


\subsection{Material}

O levantamento preliminar revelou uma produção pouco significativa entre os anos de 1990 a 1994 sobre o profissional da informação, levando a delimitação do período da pesquisa para 1995 a 2002. Nesta etapa, foi também identificado o título do periódico, de cada região geográfica, com maior número de artigos publicados no período sobre o tema da pesquisa, a saber:

- Região Sul: Informação \& Informação. Publicação semestral do Departamento de Ciências da Informação da Universidade Estadual de Londrina - UEL, que tem como objetivo divulgar trabalhos inéditos na área de Ciência da Informação e contribuir para a formação acadêmica dos alunos de graduação e pós-graduação, e assim colaborar na atualização e no desenvolvimento do profissional da informação. Iniciou sua publicação em 1995 e oferece a comunidade científica o periódico de forma impressa. Foram consultados os v. 0 de 1995 ao v. 6 de 2001 e os respectivos números de cada volume.

- Região Sudeste: Transinformação. Publicação semestral do Programa de Pós-Graduação em Biblioteconomia da Pontifícia Universidade Católica de Campinas. Iniciou sua publicação em 1989. Disponibiliza on-line do volume 8 de 1996 ao volume 10 de 1998. Foram consultados os v. 7 de 1995 ao v. 14 de 2002 e os respectivos números de cada volume.

- Região Centro Oeste: Ciência da Informação. Publicação do Instituto Brasileiro de Informação em Ciência e Tecnologia - IBICT, com periodicidade quadrimestral. Destinase à publicação de trabalhos originais relacionados com a ciência da Informação. Em suas diferentes seções arrola trabalhos sobre os fenômenos ligados à produção, organização, difusão e utilização de informações em todos os campos do saber. Iniciou sua publicação em 1972 e disponibiliza também a versão eletrônica (on-line) desde 1995. Foram consultados os v. 24 de 1995 ao v. 31 de 2002 e os respectivos números de cada volume.

- Região Nordeste: Informação \& Sociedade: Estudos. Publicação periódica semestral do Curso de Mestrado em Ciência da Informação da Universidade Federal da Paraíba UFPB. Tem como principal objetivo disponibilizar textos inéditos, previamente avaliados sobre a relação entre a informação e a sociedade. Disponibiliza também a versão eletrônica (on-line) da publicação desde 1991. Foram consultados os v. 5 de 1995 ao v. 12 de 2002 e seus respectivos números.

- Região Norte: Não foi identificado nenhum título de periódico 


\subsection{Procedimentos}

Foram utilizados todos os volumes e todos os números dos periódicos selecionados publicados no período de 1995 a 2002. O critério utilizado para enquadrar os artigos, dentro do tema da pesquisa, foi a presença do termo profissional da Informação e/ou Bibliotecário no título, no resumo e/ou como palavras-chave. Após esta seleção, efetuou-se a cópia dos artigos para leitura e avaliação. Do levantamento, resultou o quantitativo de 47 artigos que foram analisados e avaliados neste trabalho (Quadro 1).

\section{Quadro 1 - Título dos periódicos avaliados, por região geográfica do Brasil}

\begin{tabular}{|l|c|}
\hline TITULO DO PERIÓDICO & N. ART. \\
\hline Transinformação - Região Sudeste & 15 \\
\hline Informação \& Informação - Região Sul & 13 \\
\hline Informação \& Sociedade - Região Nordeste & 11 \\
\hline Ciência da Informação - Região Centro Oeste & 8 \\
\hline Total de artigos & $\mathbf{4 7}$ \\
\hline
\end{tabular}

Da coleção dos títulos analisados, no período de 1995 a 2002, ficou faltando o v. 14, n. 2 de jul./dez. de 2002 da Revista Transinformação e o v. 7, n. 1 e n. 2 da Revista Informação \& Informação de 2002, que não foram publicados e/ou distribuídos até a data de fechamento do levantamento dos dados. Pode-se considerar uma limitação da pesquisa a questão da pontualidade da publicação, considerada a correspondência entre o último número e a data devida de entrega da revista à comunidade científica. Por outro lado, destaca-se a vantagem da coleta dos dados em periódicos que possuem sua versão também on-line, pela rapidez de acesso aos mesmos.

\section{PROFISSIONAL DA INFORMAÇÃO: ANÁLISE TEMÁTICA}

$\mathrm{O}$ artigo deveria obrigatoriamente abordar as competências, os conhecimentos, as habilidades e atitudes, do profissional da informação para desempenhar seu papel, funções e atribuições na Sociedade da Informação e do Conhecimento. Pela análise dos textos, observou-se que não há um consenso entre os autores dos artigos em relação aos termos como: competências, conhecimentos, habilidades, atitudes, funções e atribuições. Nesse sentido, nossa análise se deu no sentido de: 1) agrupar os conhecimentos e habilidades do profissional da informação; 2) agrupar as funções e atribuições do profissional da Informação; 3) conceituar competência profissional. 


\subsection{Conhecimentos e habilidades do profissional da informação.}

Visando maior compreensão do tema, buscou-se a definição de alguns termos. Para Griffiths e King, (1980) citado por Alencar (1996), "uma competência é um conhecimento, habilidade ou atitude de uma pessoa que está casualmente relacionada com um comportamento eficaz demonstrado através de critério de desempenho". Targino (2000) entende "requisitos como condições essenciais à consecução de objetivos e fins determinados, o que, em última instância, significa habilidade ou capacidade para (...)”.

Os conhecimentos e habilidades que deve possuir o profissional da informação, apontados pelos autores dos artigos, foram agrupados nos seguintes eixos temáticos:

Tratamento da Informação

- Atividades de descrição física, análise temática, condensação e representação temática (GUIMARÃES, 1997);

- Capacidade de análise face à diversificação de suportes, à multiplicidade de uso da informação e às demandas informacionais (TARGINO, 2000);

- Localizar e disseminar informação de qualidade e criar consciência estratégica para a capacitação de informação de interesse (MARCHIORI, 2002);

- Priorizar a qualidade da informação no que diz respeito à exatidão, utilidade, aplicabilidade e meio de difusão (MARCHIORI, 2002);

- Utilizar metodologias para o desenvolvimento de sistemas de informação (MARCHIORI, 2002);

\section{Gestão e administração da informação}

- Conhecimento de estruturas alternativas de administração e suas implicações para operacionalização de bibliotecas (ALENCAR, 1996);

- Gerência de Unidades e Sistemas de Informação (GUIMARÃES, 1997);

- Gerenciamento no sentido de oferecer serviços custo/efetivos, que sejam receptivos à novas idéias, que possam adaptar seus serviços às constantes mudanças organizacionais (JOHNSON, 1998);

- Contribuir para a definição de uma política de informação, participando da reflexão estratégica da organização, criando dinâmicas e contribuindo para a inovação (VOLANT, 1995, citado por ODDONE, 1998);

- Assegurar a coerência entre sistema de informação global e os subsistemas locais, assim como a coerência dos métodos e das ferramentas, permitindo a elaboração da engenharia documentária (VOLANT, 1995 citado por ODDONE, 1998); 
- Aplicar métodos e ferramentas de gestão de recursos e de inteligência organizacional, de recursos humanos e de gestão de organização de informações (PONJUAN DANTE, 1999);

- Visão gerencial para tomar decisões, de forma racional e eficiente, diante de questões como custo da informação e seu caráter estratégico (TARGINO, 2000);

- Desenvolver pensamento crítico e analítico para entender problemas de informação e comunicação, conforme as perspectivas técnicas, tecnológicas, organizacionais e pessoais (MARCHIORI, 2002);

Tecnologia da Informação

- Conhecimento e entendimento não somente das práticas tradicionais em gerenciamento da informação, mas também dos últimos desenvolvimentos tecnológicos (JOHNSON, 1998);

- Conhecimentos e habilidades provindas de outros setores da indústria da informação (JOHNSON, 1998);

- Dominar as ferramentas, adaptando os avanços tecnológicos para um uso apropriado (VOLANT, 1995 citado por ODDONE, 1998);

- Alfabetização digital e estar constantemente atualizado perante as novas tecnologias (OLIVEIRA et al., 2000);

- Domínio das técnicas de buscas informatizadas e entusiasmo pelas tecnologias (OLIVEIRA et al., 2000)

- Administrar com a tecnologia de informação, analisando criticamente o seu custo, qualidade e complexidade (MARCHIORI, 2002);

- Conhecimentos de informática: redes de informação, sistemas gerenciadores de bases de dados, hardware, produtos em CD-Rom e multimídia, tecnologia de imagem (MARCHIORI, 2002).

- Se valerem cada vez mais das seguintes tecnologias de informação: redes de informação; bases e bancos de dados on-line; bibliotecas virtuais e softwares (PEREIRA e RUTINA, 2001).

Atendimento e Interação com os Usuários

- Orientar os usuários a tratar com o excesso de informações (JOHNSON, 1998);

- Desenvolver habilidades de treinamento para ajudar as pessoas a usarem não somente as bibliotecas, mas igualmente as fontes de informação disponíveis em qualquer tipo e meio (JOHNSON, 1998);

- Entendimento de como capacitar o usuário na busca de informação que demanda (JOHNSON, 1998); 
- Produzindo valor agregado e prestando assessoria às esferas decisórias e operacionais da organização, em suas necessidades de informação (VOLANT, 1995, citado por ODDONE, 1998);

- Motivando os atores à utilização das informações, formando os usuários na aplicação dos métodos e das técnicas de pesquisa e de tratamento da informação (VOLANT, 1995 citado por ODDONE, 1998);

- Contribuindo para a autonomia dos indivíduos e para a aprendizagem coletiva, desenvolvendo uma verdadeira cultura de informação (VOLANT, 1995 citado por ODDONE, 1998)

- Capacidade orientada para o diálogo com o cliente e com seus pares (BERAQUET et al., 1999);

- Sensibilidade às necessidades dos usuários (ARRUDA, 2000);

- Ser capaz de perceber o comportamento de seus usuários ou clientes e que ofereça um serviço adequado à sua forma de agir (OLIVEIRA et al. 2000);

- Auxiliar na definição das atividades dos usuários e na explicitação de suas necessidades de informação (MARCHIORI, 2002);

- Priorizar informações relevantes para o usuário e/ou grupos de usuários (MARCHIORI, 2002);

- Personalizar a forma de apresentação da informação (MARCHIORI, 2002).

Atitudes e qualidades pessoais

- Atitudes corretas e qualidades pessoais, boas habilidades interpessoais, habilidade de liderança (JOHNSON, 1998);

- Contribuir para a resolução de problemas, para a fertilização do saber, para a abordagem interdisciplinar e para o questionamento (VOLANT, 1995 citado por ODDONE, 1998)

- Atitudes pessoais como simpatia, criatividade, confiança, entusiasmo e outros (OLIVEIRA et al., 2000);

- Capacidade de comunicação e de fazer alianças, capacidade de inovação. Persistência, responsabilidade, profissionalismo, tolerância no convívio com os demais (TARGINO, 2000);

- Criatividade na busca de novas soluções para velhos problemas. Inclui criticidade, originalidade, liderança, sensibilidade diante de situações novas, flexibilidade e eficiência (TARGINO, 2000); 
- Um conjunto de capacitações informais como flexibilidade a mudanças e a tarefas, adaptabilidade, capacidade de trabalhar em grupo (ARRUDA, 2000);

- Atualização constante através de leitura, estudo e pesquisa. Motivação pessoal, visão interdisciplinar (TARGINO, 2000);

- Educação continuada (ARRUDA, 2000).

\subsection{Funções e atribuições do profissional da informação}

Função é definida por Alencar (1996) como "ação própria natural de um órgão". Para Mostafa e Pacheco (1995), corresponde a "um conjunto de atividades análogas, interdependentes e especializadas". De acordo com Tarapanoff (1999) e Targino (2000), o que caracteriza a profissão do Bibliotecário e do profissional da informação é o ciclo documentário ou informacional e que, tradicionalmente, centram suas ações em torno de cinco funções primordiais, mas alertam as autoras que os desdobramentos dessas funções não vão desaparecer, mas no espaço virtual terão novas aplicações. As cinco funções básicas são: Seleção; Descrição; Interpretação; Disseminação; Preservação dos documentos e das informações (inclusive os documentos eletrônicos).

Para Targino (2000, p. 66) é importante que, o profissional da informação,

Não perca de vista a sua característica primordial de responsável pelo ciclo documentário e informacional privilegiando a busca e o acesso a fontes de informação onde quer que estejam, com a finalidade precípua de suprir as necessidades informacionais de indivíduos e coletividades.

Segundo Wormell (1999, p. 7)

O papel clássico do bibliotecário tem sido sempre o de guiar e aconselhar usuários nas suas buscas por informação. Qualquer que seja o nível das tecnologias disponíveis na área de Biblioteconomia e Ciência da Informação, o trabalho do bibliotecário tem sido mediar provedores, sistemas e usuários da informação. Tradicionalmente, esta tem sido uma função didáticoeducativa, caracterizada pelo trabalho de um indivíduo com um profundo e criterioso conhecimento da natureza e do ambiente informativo.

Para Wormell $(1999$, p. 8) o profissional da informação desempenha papéis e funções, em sua maioria ligadas ao usuário ou ao trabalho com profissionais de tecnologias da informação e destaca as seguintes:

- Facilitar o uso da informação

- Navegar entre sistemas de conhecimento e fontes de informação

- Oferecer consultoria e aconselhamento para problemas de informação

- Examinar e oferecer um ótimo gerenciamento de recursos de informação 
- Oferecer serviços de tradução entre várias línguas

- Traduzir sistemas técnicos e culturais entre si

- Transformar dados e favorecer o fluxo de dados entre sistemas

- Conectar contextos sociais e culturais

- Educar/treinar os usuários

- Prover esclarecimentos sobre recursos de informação

- Oferecer suporte às políticas de informação para as estratégias da organização

Rutina e Pereira (2000, p. 26) enfocam no artigo os desafios e atributos de relacionamento dos gestores de Unidades de Informação, entendendo que, através dessas atribuições, os mesmos gozarão de maior empatia da parte de seus colaboradores, usuários e fornecedores, ao:

- Saber chefiar e liderar por meio de uma administração participativa, que suprima o discurso do "eu", para o discurso do "nós";

- Recrutar e selecionar pessoas que se adaptam rapidamente ao novo local de trabalho;

- Gerenciar equipes de trabalho com uma justa divisão de tarefas e de responsabilidades;

- Qualificar e motivar seus recursos humanos para os objetivos traçados;

- Saber delegar informações e autoridade, descentralizando as decisões, pois são através delas que se obtém agilidade na empresa;

- Propiciar o autoconhecimento pessoal, visando a integração grupal, ao fortalecer o espírito de equipe;

- Avaliar as potencialidades de sua equipe de trabalho, promovendo uma avaliação de desempenho (...)

Para Rutina e Pereira (2000, p. 26),

Os gestores de unidades de informação eficazes são aqueles que atingem resultados através de pessoas (equipes) motivadas e unidas, sabem como estabelecer metas pessoais e profissionais em suas carreiras, ou seja, têm um novo perfil: o de gestores-empreendedores, que sabem conquistar e manter seus usuários, levantando suas necessidades, expectativas e desejos e a partir daí, surpreendê-los positivamente com novos produtos e/ou serviços. Vêem na qualidade do atendimento aos usuários e na criatividade, os grandes diferenciais nos níveis de satisfação: Portanto, os novos desafios para esses gestores são agora: criatividade e profissionalismo.

Lucas (1996, p. 4), a partir de uma revisão de literatura reflete sobre a função dos profissionais da informação nos atuais modelos de organização do conhecimento, frente a realidade das tecnologias de informação, e constata que, este contexto requer "um profissional com o perfil de analista simbólico, capaz de utilizar eficaz e criativamente o conhecimento disponível nos sistemas informatizados"e que deverá apresentar as seguintes características:

- Oferecem produtos não padronizados;

- São os intermediários, identificando e resolvendo problemas a partir de palavras, representações e símbolos;

- São consultores, engenheiros, projetistas de sistemas, cientistas, incluindo os especialistas no manejo da informação e em desenvolvimento das organizações; 
- São capazes de criar e inovar com base em experiência cumulativa;

- A qualidade, originalidade, rapidez e oportunidade surgem como resultado de problemas resolvidos;

- Têm habilidade para identificar, intermediar e resolver problemas.

\subsection{Definindo Competência Profissional}

As Diretrizes curriculares do MEC - Ministério da Educação e do Conselho Nacional de Educação, para os Cursos de Biblioteconomia, foram aprovadas em 03 de abril de 2001. Dentre as competências e habilidades dos graduados em Biblioteconomia enumeram-se as típicas desse nível de formação, agrupadas em competências e habilidades gerais e específicas, conforme mencionadas a seguir (MINISTÉRIO DA EDUCAÇÃO, 2001):

\section{Gerais}

- Gerar produtos a partir dos conhecimentos adquiridos e divulgá-los;

- Formular e executar políticas institucionais;

- Elaborar, coordenar, executar e avaliar planos, programas e projetos;

- Utilizar racionalmente os recursos disponíveis;

- Desenvolver e utilizar novas tecnologias;

- Traduzir as necessidades de indivíduos, grupos e comunidades nas respectivas áreas de atuação;

- Desenvolver atividades profissionais autônomas, de modo a orientar, dirigir, assessorar, prestar consultoria, realizar perícias e emitir laudos técnicos e pareceres;

- Responder a demandas sociais de informação produzidas pelas transformações tecnológicas que caracterizam o mundo contemporâneo.

\section{Específicas}

- Interagir e agregar valor nos processos de geração, transferência e uso da informação, em todo e qualquer ambiente;

- Criticar, investigar, propor, planejar, executar e avaliar recursos e produtos de informação;

- Trabalhar com fontes de informação de qualquer natureza;

- Processar a informação registrada em diferentes tipos de suporte, mediante a aplicação de conhecimentos teóricos e práticos de coleta, processamento, armazenamento e difusão da informação;

- Realizar pesquisas relativas a produtos, processamento, transferência e uso da informação.

No que tange as Diretrizes Curriculares Nacionais - DCN, do ensino de

Biblioteconomia, Souza (2002, p., 10), destaca que:

A educação bibliotecária brasileira a partir de 2001, está em novo patamar. Foi superada, formalmente, a organização do Currículo de Biblioteconomia, centrado em grades disciplinares. $\mathrm{O}$ que se tem, de agora em diante, são orientações globais, a partir da DCN dos Cursos de Biblioteconomia, que envolvem vários componentes que se articulam em projetos educacionais voltados para a formação de Bibliotecários em condições de atender ao desenvolvimento de um país que vê sua economia provocada a se integrar em âmbito mundial numa situação em que a competição está a depender quase 
que inteiramente da maior capacidade de processar mais eficazmente um volume mais denso e complexo de informações.

Encontra-se nos artigos analisados, algumas definições de competência profissional. Para Barite (2000) citado por Urra (2001, p. 93) "competencias profesionales es todo aquello que dice relación com las habilidades, las destrezas y los conocimientos teóricos-practicos necesarios para cumplir uma función especializada de um modo socialmente reconocible e aceptable". Carrillo (1998) citado por Urra (2001, p. 94) define "las competencias profesionales como la capacidad adquirida al término de um proceso de formación que se expresa en habilidades intelectuales, sociales, psicológicas y afectivas, es decir, incluye actitudes, conocimiento, y conductas implícitas em el desarrollo humano".

Em síntese, seguindo a linha de raciocínio dos autores, poderíamos afirmar que competências profissionais compreende os conhecimentos e habilidades que o profissional da informação deve ter para desempenhar as funções e atribuições específicas da profissão.

\section{PRODUÇÃO CIENTÍFICA}

Para conhecimento do comportamento da produção científica sobre o tema profissional da informação publicados no período de 1995 a 2002, foram avaliados os seguintes aspectos: produção por título de periódico; produção por ano; produção por tipo de autoria e vinculação institucional dos autores; núcleo de autores com maior produção, discutidos a seguir.

O título de periódico com maior número de artigos sobre o Profissional da Informação é a Revista Transinformação, com 32\% da produção, seguida da Revista Informação \& Informação, com 28\% e da Revista Informação e Sociedade com, 23\%, conforme Tabela 1.

Tabela 1 - Distribuição dos artigos por título de periódicos e por ano

\begin{tabular}{l|c|c|c|c|c|c|c|c|c|c}
\hline TÍTULOS dos PERIÓDICOS & $\mathbf{9 5}$ & $\mathbf{9 6}$ & $\mathbf{9 7}$ & $\mathbf{9 8}$ & $\mathbf{9 9}$ & $\mathbf{0 0}$ & $\mathbf{0 1}$ & $\mathbf{0 2}$ & Total & $\mathbf{\%}$ \\
\hline Transinformação & 0 & 5 & 1 & 0 & 3 & 4 & 2 & - & 15 & 32 \\
\hline Informação \& Informação & 3 & 2 & 1 & 1 & 2 & 2 & 2 & - & 13 & 28 \\
\hline Informação e Sociedade & 0 & 0 & 1 & 3 & 1 & 3 & 1 & 2 & 11 & 23 \\
\hline Ciência da Informação & 2 & 2 & 1 & 0 & 0 & 1 & 0 & 2 & 8 & 17 \\
\hline TOTAL & $\mathbf{5}$ & $\mathbf{9}$ & $\mathbf{4}$ & $\mathbf{4}$ & $\mathbf{6}$ & $\mathbf{1 0}$ & $\mathbf{5}$ & $\mathbf{4}$ & $\mathbf{4 7}$ & \\
\hline \% por ano & 10 & 19 & 9 & 9 & 13 & 21 & 10 & 9 & & $100 \%$ \\
\hline
\end{tabular}

Os periódicos editados em Universidades, reúnem o maior número de artigos sobre o Profissional da Informação, uma vez que três títulos são editados por Programas de PósGraduação. Infere-se que grande parcela desta produção é oriunda das dissertações 
apresentadas nos referidos programas, confirmando-se este resultado quando da vinculação institucional dos autores apresentados na Tabela 4.

$\mathrm{O}$ ano de 2000 destaca-se com maior produção no período, com 21\%. Considerando-se que em abril de 2001 foram aprovadas as diretrizes curriculares nacionais pelo MEC, muitos desses artigos resultaram das reflexões sobre o tema ocorridas na época. Por outro lado, o índice encontrado em 1996 (19\%), pode ser atribuído às discussões em torno do tema Moderno Profissional da Informação, em nível internacional e nacional.

Em relação ao tipo de autoria, considerando-se neste estudo a autoria única e a autoria múltipla, constata-se que continua prevalecendo na área de Biblioteconomia e Ciência da Informação, a autoria única com o percentual de $72 \%$ do total da produção do período, conforme Tabela 2. Na produção dos artigos, verifica-se a presença de 51 autores, o que corresponde à média de 1,08 autor por artigo, justificando assim, o predomínio da autoria única.

Tabela 2 - Distribuição dos artigos por tipo de autoria

\begin{tabular}{l|c|c|c}
\hline TÍTULO dos PERIÓDICOS & $\begin{array}{c}\text { Autoria } \\
\text { Única }\end{array}$ & $\begin{array}{c}\text { Autoria } \\
\text { Múltipla }\end{array}$ & Total \\
\hline Transinformação & 11 & 4 & 15 \\
\hline Informação \& Informação & 11 & 2 & 13 \\
\hline Informação \& Sociedade & 7 & 4 & 11 \\
\hline Ciência da Informação & 5 & 3 & 8 \\
\hline TOTAL & 34 & 13 & 47 \\
\hline $\mathbf{\%}$ & $\mathbf{7 2 \%}$ & $\mathbf{2 8 \%}$ & $\mathbf{1 0 0 \%}$ \\
\hline
\end{tabular}

Com o objetivo de confirmar se há concentração de autores que poderíamos chamar de frente de pesquisa por serem os autores mais produtivos e influentes, os mesmos foram agrupados de acordo com sua participação em relação ao tipo de autoria, conforme demonstrado na Tabela 3.

Tabela 3 - Autores mais produtivos

\begin{tabular}{|l|c|c|c|}
\hline AUTORES MAIS PRODUTIVOS & $\begin{array}{c}\text { Autoria } \\
\text { Única }\end{array}$ & $\begin{array}{c}\text { Autoria } \\
\text { Múltipla }\end{array}$ & Total \\
\hline MARCHIORI, Patrícia Zeni & 4 & 1 & 5 \\
\hline ARRUDA, Maria da Conceição Calmon & 2 & 1 & 3 \\
\hline CUNHA, Miriam Vieira da & 1 & 2 & 3 \\
\hline PEREIRA, Edmeire Cristina & 0 & 3 & 3 \\
\hline AMARAL, Sueli Sngelica do & 2 & 0 & 2 \\
\hline TARGINO, Maria das Graças & 2 & 0 & 2 \\
\hline SILVA, Edna Lúcia da & 0 & 2 & 2 \\
\hline PACHECO, Márcia R. L. & 0 & 2 & 2 \\
\hline RUTINA, Raquel & 0 & 2 & 2 \\
\hline
\end{tabular}


Por outro lado, contata-se pela Tabela 4 que somente nove autores produziram mais de um artigo sobre o tema, encontrando-se uma diversidade de autores, levando a inferir que há uma massa de jovens autores brasileiros que se enuncia, ampliando o colégio invisível, com a proliferação dos cursos de pós-graduação no Brasil (MOSTAFA e MÁXIMO, 2003).

Tabela 4 - Instituições de origem dos autores

\begin{tabular}{l|c|c|c}
\hline INSTITUIÇÕES & $\begin{array}{c}\text { Autor } \\
\text { Principal }\end{array}$ & $\begin{array}{c}\text { Autor } \\
\text { Secundário }\end{array}$ & Total \\
\hline UFPR & 8 & 5 & 13 \\
\hline PUCCAMP & 8 & 1 & 9 \\
\hline UFSC & 4 & 2 & 6 \\
\hline UDESC & 3 & 3 & 6 \\
\hline UNB & 3 & 0 & 3 \\
\hline UEL & 3 & 0 & 3 \\
\hline UFRJ & 3 & 0 & 3 \\
\hline UFिMI & 3 & 0 & 3 \\
\hline UNICAMP & 2 & 0 & 2 \\
\hline UFC & 1 & 0 & 1 \\
\hline UFRGS & 1 & 0 & 1 \\
\hline UNESP & 1 & 0 & 1 \\
\hline SENAI & 1 & 0 & 1 \\
\hline UFBA & 1 & 0 & 1 \\
\hline CPRM - Serviço Geológico do Brasil & 1 & 0 & 1 \\
\hline INSTITUIÇÓES ESTRANGEIRAS & 6 & 0 & 1 \\
\hline NÃO INFORMARAM & 0 & 0 & 6 \\
\hline
\end{tabular}

A vinculação institucional dos autores indica a grande contribuição destes oriundos da academia, constatando-se que as Universidades continuam sendo os centros produtores de conhecimento. A colaboração de autores estrangeiros foi de $12 \%$ da produção, o que corresponde a dois artigos publicados em espanhol e quatro artigos que foram traduzidos por autores brasileiros, sendo a influência estrangeira verificada também, quando da análise das citações discutidas na Tabela 7.

\section{CRUZAMENTO BIBLIOGRÁFICO}

De acordo com Mostafa e Máximo (2003, p. 97), "na abordagem histórico cultural, as citações seriam compreendidas como unidade de análise por representarem a 'visita' ou a 'consulta' ou o 'detour' que todo pesquisador faz ao produzir conhecimento". Nesse sentido, as listas de referências utilizadas nos artigos foram avaliadas no sentido de diagnosticar o número de referências por artigo, os tipos de documentos citados, a influência estrangeira na produção dos artigos, os periódicos e os autores mais citados, discutidos a seguir. 
De acordo com a Tabela 5, contata-se que os autores utilizam em média de 1 a 20 referências por artigo, índice encontrado em $62 \%$ da produção do período.

Tabela 5 - Número de referências por artigo

\begin{tabular}{l|c|c}
\hline NÚMERO DE REFERẾNCIAS & N. ARTIGOS & $\mathbf{\%}$ \\
\hline De 1 até 10 Referencias & 15 & 31,91 \\
\hline De 11 a 20 Referências & 14 & 29,79 \\
\hline De 21 a 30 Referências & 10 & 21,28 \\
\hline De 31 a 40 Referências & 5 & 10,63 \\
\hline Mais de 40 Referências & 3 & 6,39 \\
\hline TOTAL & $\mathbf{4 7}$ & $\mathbf{1 0 0 , 0 0}$ \\
\hline
\end{tabular}

Para conhecer os tipos de documentos utilizados pelos autores na produção dos textos, os mesmos foram agrupados em livros e/ou capítulos de livros, artigos de periódicos, comunicações em eventos, textos eletrônicos disponibilizados na Internet, sendo os demais tipos de documentos agrupados na categoria "outros documentos". No caso dos periódicos eletrônicos, os mesmos foram considerados na categoria periódicos e não textos eletrônicos. $\mathrm{Na}$ categoria "outros documentos" foram incluídos as teses, dissertações, relatórios de pesquisa, monografias, TCC.

Os artigos de periódicos aparecem em primeiro lugar com 45,10\% das referências seguido dos livros e/ou capítulos de livros com 35,43\% (Tabela 6).

Tabela 6 - Tipos de documentos citados

\begin{tabular}{l|c|c}
\hline Tipos de documentos citados & N. Ref. & \% \\
\hline Artigos de periódicos & 359 & 45,10 \\
\hline Livros e/ou capítulos de livros & 282 & 35,43 \\
\hline Comunicações em eventos - Anais & 65 & 8,17 \\
\hline Textos eletrônicos - Internet & 16 & 2,01 \\
\hline Outros tipos de documentos & 74 & 9,29 \\
\hline & $\mathbf{7 9 6}$ & 100,00 \\
\hline
\end{tabular}

Constata-se em mais um estudo da área de Biblioteconomia e Ciência da Informação que as comunicações em eventos continuam sendo pouco utilizadas na produção de novos conhecimentos, e que os artigos de periódicos destacam-se como os mais citados, o que se justifica, segundo Ohira e Prado (2002, p. 71), "por serem canais rápidos e atualizados de comunicação". Outro fator importante, é o fato da maioria dos periódicos brasileiros estarem disponíveis também com sua versão on-line na Internet, como comprovado por outro estudo realizado por Ohira e Prado (2000).

Com o objetivo de verificar o grau de influência da literatura estrangeira, as referências foram agrupadas por idioma: português, inglês, sendo os demais agrupados na categoria "outros idiomas" (Tabela 7). A contribuição dos trabalhos em português atingiu o 
índice de $51,76 \%$, enquanto que a influência de literatura estrangeira apresenta o percentual de $48,24 \%$ do total das referências.

Tabela 7 - Influência da literatura estrangeira nas referências dos artigos

\begin{tabular}{l|c|c}
\hline Idioma & $\mathbf{N}$. & $\mathbf{\%}$ \\
\hline Português & 412 & 51,76 \\
\hline Inglês & 332 & 41,71 \\
\hline Outros idiomas & 52 & 6,53 \\
\hline Total & 796 & 100,00 \\
\hline
\end{tabular}

Para identificação dos títulos de periódicos que constituem o núcleo central, isto é, os que foram citados nas referências pelos autores dos artigos, considerou-se critério principal que o título do periódico tenha sido citado seis vezes ou mais (Tabela 8).

Tabela 8 - Periódicos mais citados

\begin{tabular}{l|c}
\hline TITULO DO PERIÓDICO & QTDE \\
\hline Ciência da Informação & 35 \\
\hline Revista de Biblioteconomia da UFMG & 17 \\
Perspectiva em Ciência da Informação & 3 \\
\hline College \& Research Libraries & 17 \\
\hline Journal of Education for Library and Information Science & 12 \\
\hline Library Trends & 12 \\
\hline Library Journal & 11 \\
\hline FID News Bulletin & 9 \\
\hline Journal of Library Administration & 9 \\
\hline Special Libraries & 9 \\
\hline Transinformação & 8 \\
\hline Administração de Negócios - ADN/COAD & 8 \\
\hline Ciências de la Información & 6 \\
\hline Journal of Academic Librarianship & 6 \\
\hline Informação \& Informação & 6 \\
\hline Revista de Biblioteconomia de Brasilia & 6 \\
\hline Revista Brasileira de Biblioteconomia e Documentação & 6 \\
\hline The Electronic Library & 6 \\
\hline
\end{tabular}

A Revista Ciência da Informação do IBICT destaca-se como o periódico nacional com maior número de citações, seguido da Revista da Escola de Biblioteconomia da UFMG, que a partir de 1995, mudou seu nome para Perspectivas em Ciência da Informação. Dentre os periódicos estrangeiros destacam-se: College \& Research Libraries, com 17 citações; Journal of Education for Library and Information Science e Library Trends com 12 citações cada um e finalmente o periódico Library Journal, com 11 citações, explicando dessa forma, o índice encontrado na Tabela 7 que analisou a influência da literatura nacional e estrangeira na produção científica sobre o profisssional da informação. 
Da mesma forma, procurou-se conhecer quais os autores que foram citados com maior freqüência, adotando-se como critério que os mesmos tenham sido mencionados seis vezes ou mais, independente de ser citação ou auto-citação, com o objetivo de identificar se há concentração de autores que poderíamos chamar de frente de pesquisa, que seriam os autores mais produtivos e influentes (Tabela 9).

Tabela 9-Autores mais citados

\begin{tabular}{l|c}
\hline AUTORES & QTDE \\
\hline CRONIN, Blaise & 9 \\
\hline DRUCKER, Peter & 9 \\
\hline TARAPANOFF, Kira & 9 \\
\hline ARRUDA, Maria da C. Calmon & 8 \\
\hline GUIMARÃES, José Augusto & 8 \\
\hline LANCASTER, F. W. & 8 \\
\hline MARCHIORI, Patrícia Zeni & 8 \\
\hline SOUZA, Francisco das Chagas & 8 \\
\hline BOTELHO, Tânia Mara & 6 \\
\hline
\end{tabular}

Confirma-se pela análise, a presença do núcleo de autores brasileiros, considerados os autores mais influentes, com atividades profissionais envolvendo o tema profissional da informação, como José Augusto Guimarães, Patrícia Zeni Marchiori, Kira Tarapanoff e Francisco das Chagas de Souza.

\section{CONSIDERAÇÕES FINAIS}

O levantamento efetuado nos periódicos brasileiros especializados da área de Biblioteconomia e Ciência da Informação revelou que, no Brasil, as maiores reflexões sobre o tema Profissional da Informação aconteceram a partir do ano de 1995. Perceptível a participação da ABECIN e de autores professores e pesquisadores de universidades brasileiras, envolvidos com o tema. Infere-se que a partir da criação Special Interest Group of the Modern Information Professional (FID/MIP) pela FID, da realização dos Encontros das escolas de Biblioteconomia e Ciência da Informação para os estudos de harmonização curricular para o Mercosul e da aprovação das Diretrizes Curriculares Nacionais do MEC para a área de Ciência da Informação, as discussões se materializaram na grande maioria, em artigos de periódicos da área de Biblioteconomia e Ciência da Informação.

$\mathrm{Na}$ análise temática em torno dos conhecimentos e habilidades que deve possuir o profissional da informação, percebe-se uma ênfase maior em torno de cinco grandes áreas: 
- Gestão e administração da informação: visão gerencial para administração e operacionalização de Unidades e Sistemas de Informação, nos enfoques técnicos, tecnológicos, organizacional e pessoal.

- Tratamento da informação: capacidade de análise e tratamento da informação face à diversificação de suportes e formatos da informação e diante da multiplicidade de uso da mesma;

- Tecnologia da Informação: estar constantemente atualizado diante dos últimos desenvolvimentos tecnológicos e saber administrar com a tecnologia da informação;

- Atendimento e interação com o Usuário: sensibilidade às necessidades dos usuários e saber orientar os mesmos a tratar o excesso de informação e a variedade de suportes;

- Atitudes e qualidades pessoais: capacidade de comunicação, de inovação, persistência, responsabilidade, profissionalismo, criatividade, entusiasmo, flexibilidade a mudanças e acima de tudo, contribuir para a resolução de problemas.

Por outro lado, na análise temática das funções e atribuições do profissional da informação, observa-se a atuação dos mesmos centrada em cinco funções primordiais do ciclo documentário ou informacional que são: seleção, descrição, interpretação, disseminação e preservação dos documentos e das informações.

Diante da avaliação e das inúmeras opiniões dos autores sobre competência profissional do profissional da informação, concluímos que competência profissional compreende os conhecimentos e habilidades que o mesmo deve possuir para desempenhar as funções e atribuições específicas da profissão. Percebe-se a responsabilidade dos cursos de Biblioteconomia, na capacitação formal dos profissionais da informação, que devem estar constantemente atentos às mudanças que ocorrem no mercado de trabalho e nas áreas de atuação desses profissionais, no sentido de adequar o currículo para atender essas necessidades, como também, no sentido de diagnosticar e levantar novas áreas de atuação.

$\mathrm{Na}$ avaliação da produção científica sobre o tema profissional da informação, publicada nos periódicos brasileiros em Biblioteconomia e Ciência da Informação, os resultados podem ser sintetizados em: A Revista Transinformação publicou o maior número de artigos, seguido da Revista Informação \& Informação e da Revista Informação \& Sociedade, editadas por universidades. Os anos de 1996 e 2000 destacaram-se com maior produção no período. A autoria única prevalece com $72 \%$ da produção, resultante de uma diversidade de autores, oriundos das universidades brasileiras, consideradas os centros produtores do conhecimento. 
No cruzamento bibliográfico, entendido neste trabalho, como a análise das citações, constata-se que os autores utilizam nas citações os artigos de periódicos com 45\%, seguido dos livros e/ou capítulos de livros, com uma média de 1 a 20 referências por artigo de periódico. A influência estrangeira aparece em 48\% dos documentos citados, o que justifica que a Revista Ciência da Informação e Perspectiva em Ciência da Informação tenham se destacado como os periódicos mais utilizados.

Destaca-se como maior contribuição desta pesquisa, a Bibliografia que reúne 47 artigos de periódicos sobre o Profissional da Informação (Apêndice A), que poderão subsidiar outras pesquisas na área e os estudos de adequação curricular dos cursos de Biblioteconomia do Brasil.

\section{REFERÊNCIAS}

ALENCAR, Maria de Cleófas F. Serviço de referência: atitudes reveladas. Transinformação, Campinas, v. 8, n. 2, maio/ago. 1996.

ARRUDA, Maria da Conceição Calmon. Reflexos do processo de globalização na capacitação profissional. Informação \& Informação, Londrina, v. 5, n. 1, p. 61-72, jan./jun. 2000

, MARTELETO, Regina, SOUZA, Donaldo Bello de. Educação, trabalho e o delineamento de novos perfis profissionais: o bibliotecário em questão. Ciência da Informação, Brasília, v. 29, n. 3, p. 14-24, set./dez. 2000

BERAQUET, Vera Silvia Marão et al. Qualidade de ensino da FABI - Campinas face ao moderno profissional da informação. Transinformação, Campinas, v. 11, n. 1, p. 63-69, jan./jun. 1999.

CASTRO, César Augusto. Profissional da Informação: perfis e atitudes desejadas. Informação \& Sociedade: Estudos, João Pessoa, v. 10, n. 1, p. 142-156, 2000.

GUIMARÃES, José Augusto Chaves. Moderno profissional da informação: elementos para sua formação no Brasil. Transinformação, Campinas, v. 9, n. 1, jan./abr. 1997.

JOHNSON, Ian M. Desafios para o desenvolvimento profissional na "Sociedade da Informação" - algumas respostas das Escolas de Biblioteconomia e estudos de informação na Grã Bretanha. Trad. de Patrícia Zeni Marchiori. Informação \& Informação, Londrina, v. 3, n. 2, p. 7-18, jul./dez. 1998.

LUCAS, Clarinda Rodrigues. A organização do conhecimento e tecnologias da informação. Transinformação, Campinas, v. 8, n. 3, set./dez. 1996.

MAIA, Maria Helena Bier, OHIRA, Maria Lourdes Blatt. Perfil do profissional da informação almejado pelos cursos de Biblioteconomia da região sul do Brasil. Porto Alegre: ABEBD, 1998. p. 3-35. (Cadernos ABEBD, 13). 
MARCHIORI, Patrícia Zeni. "Ciberteca" ou biblioteca virtual: uma perspectiva de gerenciamento de recursos de informação. Ciência da Informação, Brasília, v. 26, n. 2, 1997 . A ciência e a gestão da informação: compatibilidades no espaço profissional. Ciência da Informação, Brasília, v. 31, n. 2, p. 72-79, maio/ago. 2002.

. Que profissional queremos formar para o século XXI - Graduação. Informação \& Informação, Londrina, v. 1, n. 1, p. 27-34, jan./jun. 1996.

MENOU, Michel J. Cultura, informação e educação de profissionais de informação nos países em desenvolvimento. Ciência da Informação, Brasília, v. 25, n. 3, p. 298-304, 1996.

MINISTÉRIO DA EDUCAÇÃO. Conselho Nacional de Educação. Diretrizes curriculares para os cursos de Biblioteconomia. Brasília, 03 de abr. 2001. Disponível em: $<$ http://www.abecin.org.br> Acesso em 21 de maio de 2003.

MOSTAFA, Solange Puntel, MAXIMO, Luis Fernando. A produção científica da Anped e da Intercom no GT da Educação e Comunicação. Ciência da Informação, Brasília, v. 32, n. 1, p. 96-101, jan./abr. 2003.

PACHECO, Márcia. O mercado emergente de informação. Ciência da Informação, Brasília, v. 24, n. 2, 1995.

MÜLLER, Rogério. Biblioteconomia: obsolência etimológica? Informação \& Informação, Londrina, v. 0, n. 0, p. 36-41, jul./dez. 1995.

NASSRI, Maria Pia G. et. al. Educação brasileira: análise temática (1991-1994) Transinformação, Campinas, v. 12, n. 1, p. 49-57, jan./jun. 2000.

ODDONE, Nanci. O profissional da informação e a mediação de processos cognitivos: a nova face de um antigo personagem. Informação \& Sociedade: estudos, João Pessoa, v. 8, n. 1, p. 25-41, 1998.

OHIRA , Maria Lourdes Blatt, PRADO, Noêmia Schoffen. Periódicos brasileiros especializados em Biblioteconomia e Ciência da Informação: evolução, Encontros Bibli, Florianópolis. n,10, out. 2000. Disponível em <http://www.ced.ufsc.br/bibliote/encontro/> Acesso em 18 de out. de 2000.

PRADO, Noêmia Schoffen. Bibliotecas virtuais e digitais: análise de artigos de periódicos brasileiros (1995/2000). Ciência da Informação, Brasília, v. 31, n. 1, p. 61-74, jan./abr. 2002.

OLIVEIRA, Ângela Maria et al. Gerenciamento do capital humano em bibliotecas ou centros de informação: desafio imposto pela sociedade do conhecimento. Transinformação, Campinas, v. 12, n. 2, p. 7-16, jul./dez. 2000.

PEREIRA, Edmeire C. ; RUTINA, Raquel. Novas tecnologias de informação e gestão em tempos de globalização. Informação e Informação, Londrina, v. 6, n. 2, p. 109-120, jul./dez, 2001. 
PONJUAN DANTE, Glória. Tendências y situación actual de las bibliotecas y unidades de información em América Latina. Informação \& Informação, v. 4, n. 1, p. 17-35, jan./jun. 1999.

RUTINA, Raquel, PEREIRA, Edmeire Cristina. O empowerment na administração de Unidades de Informação. Transinformação, Campinas, v. 12, n. 1, p. 21-29, jan./jun. 2000.

SANTOS, Jussara Pereira. O Moderno profissional da informação: o bibliotecário e seu perfil face aos novos tempos. Informação \& Informação, Londrina v. 1, n. 1, p. 5-13, jan./jun. 1996.

SOUZA, Francisco das Chagas de. Educação bibliotecária, pesquisa em educação bibliotecária e novas DCN (Diretrizes Curriculares Nacionais) do Curso de Biblioteconomia no Brasil. Informação \& Sociedade: estudos, João Pessoa, v. 12, n. 2, p. 2002.

TARAPANOFF, Kira. O profissional da informação e a sociedade do conhecimento: desafios e oportunidades. Ciência da Informação, Brasília, v. 11, n. 1, p. 27-38, jan./abr. 1999.

TARGINO, Maria das Graças. Quem é o profissional da informação? Transinformação, Campinas, v. 12, n. 2, p. 61-69, jul./dez. 2000.

URRA, Cristián Valenzuela. Competências profesionales de los egresados de la carrera de bibliotecologia de la Universidad de Playa Ancha de Ciências de la Educacion: uma propuesta para Mercosur. Transinformação, Campinas, v. 13, n. 1, p. 93-99, jan.jun. 2001.

WORMELL, Irene. Habilidades de gerenciamento e de empreendimento na profissão de Bibliotecário e Cientista da Informação. Informação \& Informação, Londrina, v. 4, n. 1, p. 7-16, jan./jun. 1999.

Nota: Pesquisa desenvolvida no Programa de Iniciação Científica - PROBIC, Curso de graduação em Biblioteconomia da Universidade do Estado de Santa Catarina - UDESC.

\begin{abstract}
Shows how the subject "Professional Workers" was mentioned in the brazilian Librarianship and Information Science periodicals between 1995 and 2002. The study of these articles envolved the following aspects: authors productivity, kind of authorship, average of citations and kind of its documents, and the core of the periodicals more frequently citated. The results shows that the Transinformação journal had published most part of the articles about this subject, 1996 and 2000 revealed the largest article publication years, the unique authorship prevails with $73 \%$ of the produce. The most part of the citations are periodicals articles $(45 \%)$, followed by books or chapters. The foreign influence is verified in $48 \%$ of the citations. The journal Ciencia da Informação is the brazilian most citated periodical. These results can contribute for the changing of the subjects in the Librarianship courses.
\end{abstract}

KEYWORDS - Informations Workers. Professional Competence. Scientific Periodicals. Scientific Article Production. 


\section{APÊNDICE A}

Relação dos artigos de periódicos sobre o profissional da informação

01 ALENCAR, Maria de Cleófas F. Serviço de referência: atitudes reveladas. Transinformação, Campinas, v. 8, n. 2, maio/ago. 1996.

02 AMARAL, Marketing e desafio profissional em unidades de informação. Ciência da Informação, Brasília, v.25, n.3, p.330-336, set./dez. 1996.

03 Sueli Angélica do. Serviços bibliotecários e desenvolvimento social: um desafio profissional. Ciência da Informação, Brasília, v.24, n. 2, 1995.

04 ARAÚJO, Vânia Hermes Rodrigues de. Conhecimento para o desenvolvimento: reflexões para o profissional da informação. Informação \& Sociedade: estudos, João Pessoa, v.9, n. 1, p. $61-75,1999$.

05 ARRUDA, Maria da Conceição Calmon. Reflexos do processo de globalização na capacitação profissional. Informação \& Informação, Londrina, v. 5, n. 1, p. 61-72, jan./jun. 2000

06 _. Reflexos do processo de globalização na capacitação profissional. Informação \& Sociedade: Estudos, João Pessoa, v. 8, n., 1, p. 11-24, 1998

07 ; MARTELETO, Regina, SOUZA, Donaldo Bello de. Educação, trabalho e o delineamento de novos perfis profissionais: o bibliotecário em questão. Ciência da Informação, Brasília, v. 29, n. 3, p. 14-24, set./dez. 2000

08 BERAQUET, Vera Silvia Marão et al. Qualidade de ensino da FABI-Campinas face ao moderno profissional da informação. Transinformação, Campinas, v. 11, n. 1, p. 63-69, jan./jun. 1999.

09 BERTO, Rosa Maria Villares de Souza. Carreira do futuro ou futuro da carreira. Transinformação, Campinas, v. 8, n. 1,jan./abr. 1996.

10 CASTRO, César Augusto. Profissional da Informação: perfis e atitudes desejadas. Informação \& Sociedade: Estudos, João Pessoa, v. 10, n. 1, p. 142-156, 2000.

11 CAVAlCANTE, Lídia Eugênia. Gestão estratégica de recursos humanos na era da tecnologia da informação e da globalização. Informação \& informação, Londrina, v. 5, n. 2, p. 139-147, jul./dez. 2000.

12 CUNHA, Miriam Vieira da. O profissional da informação e o mercado de trabalho. Informação \& Sociedade: Estudos, João Pessoa, v. 10, n. 1, p. 159-167, 2000.

13 ; SILVA, Edna Lúcia da. A produção do conhecimento na formação de profissionais da informação. Informação \& Sociedade: Estudos, João Pessoa, v. 11, n. 2, 2001. 
14 EGGERT-STEINDEL, Gisela et al. Práticas bibliotecárias: a formação, a auto-formação e atuação dos primeiros bibliotecários catarinenses. Informação \& Sociedade: Estudos, João Pessoa, v. 12, n. 2, 2002

15 GUIMARÃES, José Augusto Chaves. Moderno profissional da informação: elementos para sua formação no Brasil. Transinformação, Campinas, v. 9, n. 1, jan./abr. 1997.

16 JANNUZZI, Paulo de Martino; MATTOS, Fernando Augusto Mansor de. Duas décadas de conjuntura econômica, de (des)emprego industrial e de inserção dos profissionais da informação no mercado de trabalho. Transinformação, Campinas, v. 1, n. 2, p. 111-129, jul./dez. 2001.

17 JOHNSON, Ian M. Desafios para o desenvolvimento profissional na "Sociedade da Informação" - algumas respostas das Escolas de Biblioteconomia e estudos de informação na Grã Bretanha. Trad. de Patrícia Zeni Marchiori. Informação \& Informação, Londrina, v. 3, n. 2, p. 7-18, jul./dez. 1998.

18 LOPES, Claudia. Novas tecnologias: a Intranet como fator de mudança para as unidades de informação. Informação \& Informação, Londrina, v. 6, n. 1, p. 7-12, jan./jun. 2001.

19 LUCAS, Clarinda Rodrigues. A organização do conhecimento e tecnologias da informação. Transinformação, Campinas, v. 8, n. 3, set./dez. 1996.

20 MARCHIORI, Patrícia Zeni. Bibliotecários, jornalistas e informáticos: a ocupação de posições relativas no campo de atividades de informação. Transinformação, Campinas, v. 8, n. 1, jan../abr. 1996.

21 "Ciberteca" ou biblioteca virtual: uma perspectiva de gerenciamento de recursos de informação. Ciência da Informação, Brasília, v. 26, n. 2, 1997.

22 . A ciência e a gestão da informação: compatibilidades no espaço profissional. Ciência da Informação, Brasília, v. 31, n. 2, p. 72-79, maio/ago. 2002.

23 . Que profissional queremos formar para o século XXI - Graduação. Informação \& Informação, Londrina, v. 1, n. 1, p. 27-34, jan./jun. 1996.

24 ; PACHECO, Márcia R. L. Integração dos profissionais de informação: o futuro em sinergia. Informação \& Sociedade: Estudos, João Pessoa, v. 2, n. 2, p. 55-58, jul./dez. 1997.

25 MARENGO, Lúcia. A sociedade de informação e o mercado de trabalho. Transinformação, Campinas, v. 8, n. 1, jan./abr. 1996.

26 MENOU, Michel J. Cultura, informação e educação de profissionais de informação nos países em desenvolvimento. Ciência da Informação, Brasília, v. 25, n. 3, p. 298-304, 1996.

27 MOREIRA GONZÁLEZ, Jose Antonio. Mercado de trabajo y competências profesionales em Biblioteconomia y Docvumentación: técnicas aplicables a su investigación. Informação \& Sociedade: estudos, João Pessoa, v. 8, n. 1, p. 124-151, 1998. 
28 MOSTAFA, Solange Puntel, PACHECO, Márcia. O mercado emergente de informação. Ciência da Informação, Brasília, v. 24, n. 2, 1995.

29 MÜLLER, Rogério. Biblioteconomia: obsolência etimológica? Informação \& Informação, Londrina, v. 0, n. 0, p. 36-41, jul./dez. 1995.

30 MULLER, Mary Stela. Mudar é preciso. Informação \& Sociedade: Estudos, João Pessoa, v. 0, n. 0. p. 42-46, jul./dez. 1995.

31 ODDONE, Nanci. O profissional da informação e a mediação de processos cognitivos: a nova face de um antigo personagem. Informação \& Sociedade: estudos, João Pessoa, v. 8, n. 1, p. 25-41, 1998.

32 OLIVEIRA, Ângela Maria et al. Gerenciamento do capital humano em bibliotecas ou centros de informação: desafio imposto pela sociedade do conhecimento. Transinformação, Campinas, v. 12, n. 2, p. 7-16, jul./dez. 2000.

33 OLIVEIRA, Silas Marques de. Correlação entre atuação e gerentes de S.I, e aspectos gerenciais considerados importantes. Transinformação, Campinas, v. 12, n. 2, p. 29-50, jul./dez. 2000.

34 PEREIRA, Edmeire C. ; RUTINA, Raquel. Novas tecnologias de informação e gestão em tempos de globalização. Informação e Informação, Londrina, v. 6, n. 2, p. 109-120, jul./dez, 2001.

35 PONJUAN DANTE, Glória. Tendências y situación actual de las bibliotecas y unidades de información em América Latina. Informação \& Informação, v. 4, n. 1, p. 17-35, jan./jun. 1999.

36 ROQUE, Sonia Iraina da S. ; OHIRA, Maria Lourdes Blatt. O estágio curricular em biblioteconomia: relato de pesquisa. Informação \& Sociedade: Estudos, João Pessoa.v. 10, n. 2, p. 175-189, 2000.

37 RUTINA, Raquel, PEREIRA, Edmeire Cristina. O empowerment na administração de Unidades de Informação. Transinformação, Campinas, v. 12, n. 1, p. 21-29, jan./jun. 2000.

38 SANTOS, Jussara Pereira. O Moderno profissional da informação: o bibliotecário e seu perfil face aos novos tempos. Informação \& Informação, Londrina v. 1, n. 1, p. 5-13, jan./jun. 1996.

39 SILVA, Edna Lúcia da ; CUNHA, Miriam Vieira da. A formação profissional do século XXI: desafios e dilemas. Ciência da Informação, Brasília, v. 31, n. 3, p. 77-82, set./dez. 2002.

40 SOUZA, Francisco das Chagas de. Educação bibliotecária, pesquisa em educação bibliotecária e novas DCN (Diretrizes Curriculares Nacionais) do Curso de Biblioteconomia no Brasil. Informação \& Sociedade: estudos, João Pessoa, v. 12, n. 2, p. 2002.

41 TARAPANOFF, Kira. O profissional da informação e a sociedade do conhecimento: desafios e oportunidades. Ciência da Informação, Brasília, v. 11, n. 1, p. 27-38, jan./abr. 1999. 
43 TARGINO, Maria das Graças. Práxis bibliotecária. Informação \& Sociedade: Estudos, João Pessoa, v. 7, n. 1, p. 39-53, 1997.

42 _. Quem é o profissional da informação? Transinformação, Campinas, v. 12, n. 2, p. 61-69, jul./dez. 2000.

44 URRA, Cristián Valenzuela. Competências profesionales de los egresados de la carrera de bibliotecologia de la Universidad de Playa Ancha de Ciências de la Educacion: uma propuesta para Mercosur. Transinformação, Campinas, v. 13, n. 1, p. 93-99, jan./jun. 2001.

45 VALENTIM, Marta L. P. Assumindo um novo paradigma na Biblioteconomia. Informação \& Informação, Londrina, v. 0, n. 0, p. 2-6, jul./dez. 1995.

46 WITTER, Geraldina Porto. Profissional da informação: caracterização e busca de instrumentos para avaliação. Transinformação, Campinas, v. 11, n. 1, p. 47-53, jan./abr. 1999.

47 WORMELL, Irene. Habilidades de gerenciamento e de empreendimento na profissão de Bibliotecário e Cientista da Informação. Informação \& Informação, Londrina, v. 4, n. 1, p. 7 16, jan./jun. 1999.

Originais recebidos em 07/08/2003 